\title{
MÍDIA E DIREITO PENAL: Articulação e Influência nos Direitos Fundamentais do Acusado
}

Rejane Francisca dos Santos Mota*

Resumo: O presente trabalho versa sobre as relações entre mídia e o Direito Penal no Brasil. Para tanto, trata-se de uma análise que perpassa a construção dos processos de representação social, de modo a entender como se constroem as notícias sobre fatos criminosos no interior da Mídia. Assim verifica-se a construção da figura do crime e do criminoso, relacionando isto a imagem que o Direito Penal apresenta na sociedade brasileira, analisando a consequência dessa relação nos direitos fundamentais do acusado.

Palavras-chave: Mídia; Direito Penal; Acusado; Direitos Fundamentais

\section{MEDIA AND CRIMINAL LAW: Articulation and Influence on Fundamental Rights of Defendant}

\begin{abstract}
This paper deals with the relationship between media and criminal law in Brazil. To do so, it is an analysis that goes through the construction of the processes of social representation, in order to understand how the news about criminal acts within the Media is constructed. Thus, the construction of the figure of the crime and of the criminal is verified, relating this to the image that the Criminal Law presents in Brazilian society, analyzing the consequence of this relation in the fundamental rights of the accused.
\end{abstract}

Keywords: Media; Criminal Law; Accused; Fundamental Rights

\section{INTRODUÇÃO}

\footnotetext{
* Mestranda em Direito e Novas Relações Sociais na Universidade Federal da Bahia. Pós-graduada em Direito e Processo do Trabalho pela Fundação Faculdade de Direito da Universidade Federal da Bahia. Graduada em Direito pela Universidade Federal da Bahia. Graduada em Comunicação Social com Habilitação em Relações Públicas pela Universidade do Estado da Bahia. Advogada.
} 
Dentre os poderes estabelecidos na sociedade moderna, não há dúvida de que a mídia é um elemento fundamental, seja na manutenção do regime democrático, seja ao exercer seu papel de fiscalizador das instituições ou no papel de informar. Estes papéis sociais são expressos. Assim, levando-se em consideração os papéis que são exercidos implicitamente, como a formação de representações sociais e a formação da opinião pública, observa-se que a relevância social da mídia é muito mais vultosa.

A leitura que se faz do mundo não é direta, ao contrário, é mediada, muitas vezes pela mídia. Contudo, não são os fatos em si que chegam ao cidadão, mas os relatos que subsistem os fatos. Estes relatos são julgamentos, percepções entendimentos selecionados pelos que operam os meios de comunicação de massa. O homem lê o mundo pela Mídia e esta tradução da realidade social é que determina a memória social.

Diante desta pujante importância é que se partindo do pressuposto da onipresença da mídia, faz necessário avaliar como o campo midiático dialoga com o campo jurídico. Nessa articulação nem sempre há um esforço em traduzir a realidade com verossimilhança. Em muitas oportunidades há um exagero ou uma banalização que trazem implicações na recepção e no modo com que o público enfrenta determinadas questões sociais.Com o campo jurídico penal ocorre este processo. A mídia apropria-se de fatos criminosos e os traduz adaptando-os à sua linguagem e as suas determinações segundo a gramática.

O presente artigo, por meio do método hipotético-dedutivo e observacional efetivando uma pesquisa bibliográfica, apresenta-se com o escopo de discutir essa articulação entre o campo midiático e o campo jurídico, especialmente o campo jurídico penal. Colima-se a reflexão sobre o modo como a mídia representa este ramo do Direito e consequentemente, como esta tradução reflete na imagem que tem este ramo perante a sociedade. Ademais, traz-se à pauta a abordagem sobre a apresentação da figura do criminoso e do fato do crime na Mídia, cotejando estes aspectos com a tendência hodierna de espetacularização de fatos sociais que a Mídia engendra e a consequência disso os direitos fundamentais do acusado. 
1. REPRESENTAÇÃO DO DIREITO PENAL NA MÍDIA - ESPETACULARIZAÇÃO (CRIME E CRIMINOSO)

O Direito Penal fascina não só os seus operadores, como também, antes de mais nada, a própria sociedade. Ana Elisa Bechara opina que as questões de natureza penal despertam nos indivíduos os sentimentos primitivos. (2008).

Este ramo do Direito atrai o público pelo fato de estar mais relacionado às emoções e a fatos que sensibilizam o indivíduo. Como seu objeto precípuo é o crime e este é uma ação contra alguém ou alguma coisa, incluindo aqui valores que estão diretamente relacionados à vida social e a paz social, um fato delituoso gera maior comoção social.

A comoção ainda está relacionada ao fato da sanção que a prática delituosa encerra. Por ser o fato criminoso algo que agride a valores tutelados pela ordem jurídica como mais importantes e que demandam a intervenção de um ramo do Direito que age com mais gravidade, suas sanções são mais severas e incisivas, mormente quando a principal é a possibilidade de restrição à liberdade de alguém. $\mathrm{O}$ isolamento que as sanções penais pode possibilitar causa maior clamor social, fazendo com que o apelo social diante de crimes e de assuntos relacionados a este ramo seja pujante. Luiz Werneck Vianna define esse fenômeno como “judicialização” das relações sociais (2008).

Segundo Werneck Vianna, esta judicialização decorre do isolamento do cidadão diante da deserção dos principais “atores” da vida pública: numa conjuntura onde Estado, partidos, escolas, religiões e família falham na busca de padrões éticos consistentes, a moralidade enxerga refúgio neste "direito em tempo real”, fazendo de delegados, promotores, juízes e ministros as grandes estrelas do drama nacional (2008).

A relação midiático-jurídica também se pauta na criação de representações sobre as figuras do crime e do criminoso, de modo que se operam algumas exclusões que decorrem das categorias construídas. O discurso, então, serve para justificar algumas situações, legitimá-las socialmente e para obscurecer realidades que se deseja escamotear por parte do Estado e dos detentores do poder. 
Neste sentido:

[...] questão a ser ressaltada é o efeito do que se produz na imprensa nos leitores, nos cidadãos, uma vez que ao noticiar eventos, como crime, por exemplo, a mídia contribui para fornecer quadros de interpretação ao leitor sobre o sistema penal, sobre o crime, sobre o criminoso na sociedade e sobre as próprias vítimas (JUHEM apud PETRARCA, 2007).

Acrescenta Fernanda Petrarca, sobre o poder da mídia na construção de representações:

Ao mesmo tempo, ela também intensifica a legitimidade do sistema penal, reforçando o seu papel na sociedade. As matérias fornecem imagens e representações sobre o agressor, o qual pode eventualmente ser definido como "doente mental”, ou como assassino, e sobre as vítimas, que por vezes podem ser apontadas como estimuladoras da situação. (2007).

Para compreender como a mídia constrói categorias é fundamental que se considere a forma como ela está estruturada e as relações que estabelece com outros campos sociais.

O universo jornalístico dentro do campo midiático se configura com estrutura e regras próprias. Há determinação tanto em relação à inter-influência entre os jornalistas, entre as empresas jornalistas (determinada pela concorrência), tanto em relação a outras fontes de poder e em relação a ao público. Neste aspecto é que é determinante a relação com os números indicativos de audiência e as estratégias que são utilizadas para atrair o público.

As notícias de variedade, tais como o crime e o drama, constituem um dos princípios de seleção jornalístico do que é o sensacional, o espetacular, o excepcional. Busca-se aquilo que atrairá a atenção do público numa tentativa de não gerar o questionamento e banalizar certas situações da vida cotidiana. Isso é, não causar reflexão quanto aquilo que está sendo noticiado, mas divertir. Pierre Bourdieu designa este tipo de objeto jornalístico como "os fatos ônibus”. Estes se constituem em notícias de variedade, as quais frequentemente geram consenso, uma vez que todos identificam nela algo comum e, além disso, elas não promovem conflitos (BOURDIEU, 1997).

O jogo de poder e influência se estabelece também no que diz respeito à escolha do que será notícia. Trata-se de um procedimento que envolve uma negociação no interior do jornalismo, que envolve um escalonamento de importância de temas (primando-se por aqueles que envolvam o interesse público), como também envolve a concorrência com outros jornais. 
Segundo Fernanda Petrarca :

O crime é um destes fatos, uma vez que apesar de haver discordância sobre o que pode ser considerado crime todos acreditam na sua punição, pois se houve delito, deve haver pena e assim a mídia legitima o sistema penal, sobretudo por meio de seus programas policiais. (2007).

Para a mesma autora, o crime enquanto fato a ser noticiado apareceu inicialmente nos jornais ingleses e americanos em meados do século XIX. Entretanto, somente em meados do século $\mathrm{XX}$, a reportagem policial e as notícias relacionadas ao setor policial dos jornais passaram a ser atração da imprensa, com o surgimento da imprensa comercial e com a origem do que foi designado como "penny press”. Nos Estados Unidos, o “penny press” se constitui como uma estratégia importante para diferenciar o jornalismo de outras atividades profissionais neste país e para definir um corpo profissional cuja atividade voltava-se para a busca no novo, instaurando a novidade como princípio de seleção. (2007).

No Brasil, por sua vez, as matérias policiais também se destacaram com o surgimento do jornalismo comercial, com o advento da reportagem e com o surgimento da figura do repórter como um tipo específico de atividade jornalística que tem por objetivo apurar o que ocorre nas ruas, nas periferias, e também nas delegacias de polícia. Contudo, ao contrário do que aconteceu em outras situações nacionais, a reportagem não aparece associada a uma distinção fundamental com outros campos sociais, como um saber fazer que precisava se diferenciar o que era produzido em outros campos. A reportagem, no Brasil, surge associada a um conhecimento obtido em outros âmbitos e universos sociais, sobretudo o campo político e cultural (PETRARCA, 2007).

Uma nuance do jornalismo no Brasil foi a articulação existente entre o jornalismo policial e outros campos. Inicialmente os jornalistas eram delegados de polícia. Posteriormente, com o ingresso de muitos escritores no jornalismo a atividade passou a ser vista como uma maneira de não só seguir uma carreira política, mas também literária. Segundo Fernanda Petrarca, em meados da década de 1950 as editorias de polícia que contavam, na maioria das vezes, com repórteres que eram policiais e com delegados, passaram a adotar um outro estilo de narrar o policial através do romance. A utilização da romancização nas notícias, permitia dar perfil ao 
personagem, ao vilão e foi introduzido principalmente no jornalismo brasileiro por Nelson Rodrigues com a coluna “A Vida Como Ela É”, do jornal Última Hora carioca . (ABREU paud PETRARCA, 2007).

A consequência da articulação exacerbada que hodiernamente tem se pautado entre a mídia e o Direito Penal está no fato da substituição da Mídia pelos operadores do Direito. Isto é, tem havido uma confusão de competências de modo que aquilo que outrora se restringia a noticiar os fatos, informando a sociedade sobre o acontecia, transmudou-se para a efetuação de um poder de julgar que se antecipa e, em certa medida, supera o poder jurisdicional que deveria ser exclusivo do Poder Judiciário.

Sobre esse aspecto Ana Elisa Bechara esclarece:

Se antes tínhamos uma imprensa que buscava, de forma ativa, influenciar os operadores do sistema jurídico-penal, hoje estamos diante de meios de comunicação que pretendem se substituir aos próprios tribunais, esforçando-se para realizar, por seus próprios recursos, um julgamento virtual do caso concreto, de repercussão infinitamente superior à da própria persecução penal. (2008).

A abordagem que é feita dos fatos criminosos é veiculada como entretenimento, assim, utiliza-se o mecanismo da ficcionalização, na qual crimes se tornam acontecimentos fantásticos e há uma banalização da dor humana em função do enfoque trágico, quase novelístico. Há uma transformação do cidadão em personagem. Percebe-se com isso que os meios de comunicação tendem a dramatizar notícias relacionadas a crimes, especialmente quando implicam crianças e adolescentes, como nos casos de pornografia infantil e homicídio. Tudo isso vai aumentando a sensação de insegurança e de vulnerabilidade, e se traduz em uma maior demanda de intervenção por parte do Direito Penal. (PUIG apud BECHARA, 2008).

No que diz respeito à figura do suposto criminoso, posto que até que prove o contrário, com sentença condenatória em que não caiba mais recurso, há uma absurda violação à presunção de inocência dos investigados, promovendo-se uma abusiva exposição, na qual expõem a uma sentença social de exclusão. Sendo mostrados na televisão como criminosos, dificilmente este estereótipo será retratado caso se comprove uma inocência, ademais, terá efeitos deletérios mesmo havendo comprovação de sua condenação, isto porque a exposição fará com seja 


\section{MÍDIA E DIREITO PENAL: Articulação e Influência nos Direitos Fundamentais do}

Acusado

ainda mais marginalizado no contexto social. Consoante esclarece Santiago Mir Puig, a imprensa amplia a dimensão das desgraças e da violência. Ao informar sobre fatos negativos que se produzem em todo o mundo, faz-se com que o destinatário da notícia tenha a sensação de que esses ocorrem com mais freqüência do que antes, quando só se conheciam aqueles decorrentes do próprio âmbito de vida pessoal, familiar ou profissional. (PUIG apud BECHARA, 2008).

Diante da exacerbação na veiculação de crimes e de suas circunstâncias, erige-se um clima de insegurança, exigindo-se o aumento da demanda do Direito Penal. Daí, a exigência pelo aumento das penas e pelo maior rigor nas punições, inclusive, no tocante à possibilidade de introdução de penas capitais. ${ }^{1}$ Neste quadro há um processo legislativo que se revela cada vez mais casuístico e incompetente.

Reflete Ana Elisa Bechara:

Dessa forma, ainda, a identificação da maioria social com a vítima do delito provoca importante transformação no âmbito do Direito Penal objetivo: em concreto, perde-se a visão deste como instrumento de defesa dos cidadãos frente à intervenção coativa do Estado. E, assim, a compreensão da lei penal como “magna carta” da vítima sobrepõe-se à concepção clássica do Direito Penal enquanto “magna carta” do agente, conforme expunha Von Liszt, causando reviravolta na ciência penal, a começar do próprio princípio da legalidade. (2008).

Esse Direito que é exacerbado e aplicado como primeira razão e não como ultima ratio, como deveria ser, a doutrina penalista denomina de Direito Penal de Emergência. Neste há a notória perda do caráter subsidiário e fragmentário do Direito Penal, bem como o desvirtuamento de sua missão precípua, para ser um instrumento político de segurança.

Uma nuance do Direito Penal simbólico é não se restringir a identificar determinado fato como também, ou, sobretudo, o específico tipo de autor, que é definido não como igual, mas como outro. Persegue, pois, a construção de uma determinada imagem de identidade social, mediante a definição de autores como outros, não integrados nesta identidade, por conseguinte, passíveis da exclusão. Enuncia Maunel Cancio Meliá:

\footnotetext{
${ }^{1}$ Cumpre ressaltar que a Constituição Federal autoriza pena de morte somente em caso de guerra declarada, vide art. 5, inciso XLVII, alínea “a” da Magna Carta.
} 
[...] o que ocorre em muitos outros âmbitos de 'antecipação' das barreiras de punição - mas que a regulação tem, desde o início, uma direção centrada na identificação de um determinado grupo de sujeito - 'os inimigos' - mais que na definição de um ‘fato’ (JAKOBS e MELIÁ, 2007, p. 81).

No aspecto criminal, as notícias são apresentadas de forma fragmentada. Os crimes que acontecem no dia são evidenciados como se tivessem surgido do nada e como se não tivessem sido derivados do contexto social do autor. Foca-se, tão só, no fato delituoso e na análise superficial dos personagens do espetáculo. Assim, olvida-se a dimensão social em que está imerso o fato e seus personagens, a relação entre a criminalidade e suas causas possíveis e sua consequências sociais. Arremata Marilena Chauí:

Nenhuma informação real foi transmitida à sociedade, a não ser a idéia de que criaturas más e perversas, saídas de parte nenhuma, haviam se posto, sem outro motivo a não ser a pura maldade, a ameaça a vida e os bens de cidadãos honestos e desprotegidos. (CHAUI, 2006, p. 47).

Na estruturação dos programas são levadas em consideração regras segundo as quais a guerra televisiona melhor do que a paz, uma vez que contém muita ação e sentimentos poderosos, por isso, a ênfase que é dada a violência. Da mesma forma o bizarro e os estranho televisionam muito bem. Destaca-se ainda que a morte televisiona melhor que a vida, uma vez que na morte tudo está decidido e na vida tudo é muito ambíguo e aberto a muitas possibilidades. (CHAUI, 2006, p. 57).

O modo como a televisão tem pautado a temática da violência no Brasil, tem ocasionado, segundo assevera Marilena Chaui, a banalização do mal. A imagem do mal banalizado, segundo a autora, é construída a partir de outras imagens expressas como chacina, como massacre, como guerra civil tácita. (2006, p. 115). Nesse sentido é que o Direito Penal é alçado a condição destrutor deste mal.

A violência é traduzida apenas como ato do bandido, isto é daqueles que roubam traficam ou matam. Deste modo, escamoteia-se outros aspectos da violência, tais como a discriminação e o racismo, que são também nuances da violência, tão graves quanto as outras que afetam mais diretamente alguns valores concebidos como principais dentro do ordenamento jurídico. Não 


\section{MÍDIA E DIREITO PENAL: Articulação e Influência nos Direitos Fundamentais do}

Acusado

se concebe, portanto que há violência nas relações sociais e que aquele que agride a honra e a dignidade de alguém é tão criminoso, quanto aquele que ofende o patrimônio.

Nesse contexto, o discurso que se erige sobre a violência está calcado num sistema de exclusão social, no qual os violentos, os bandidos são os outros, que merecem o pior tratamento, a quem, inclusive, não cabe discussão sobre dignidade e direitos humanos. Os criminosos são apresentados como os “outros”, que se distingue do "nós”, homens honestos e pacíficos.

Neste quadro, há comunicadores que disseminam a frase "direitos humanos para quem tem direitos”. Nesta lógica, enquadram-se os criminosos como sem direitos, criando-se um espaço de ódio em relação dos defensores dos direitos humanos aplicados a generalidade das pessoas, estes são apresentados como defensores dos bandidos contra as vítimas. O Direito Penal, assim, é utilizado como meio de exclusão social, em que aquele que comete crimes e que a mídia veicula o fato delituoso pode ser expulso da sociedade, despojado de seus direitos civis e sociais, torna-se um excluído desnecessário. Há uma culpabilização antecipada dos acusados, considerados inimigos sociais e que devem ser punidos pelas forças da ordem.

Por conseguinte:

No momento em que todos os membros da sociedade surgem unificados na qualidade de brasileiros , não só a divisão social das classes pode ser dissimulada, mas ainda a suposta violência de alguns aparece como crime de uns poucos contra todos, pois é violência contra a nação. (CHAUI, 2006, p. 134).

Verbera Marilena Chaui:

À imagem do atraso ignorante vem sobrepor-se tacitamente, outra, mais perversa: a de que “eles” estão fora do lugar, não pertencem ao novo território no qual se situaram indevidamente, formando um misto de invasão e detrito, um entulho humano que se aglomera pelas ruas e favelas, ameaçando a segurança dos legítimos proprietários do espaço privado. “Eles” são sujeira, desordem, obstáculo à imagem da sociedade una, indivisa, progressiva ou moderna. (CHAUÍ, 2006, p. 128).

Ante ao exposto, verifica-se que a articulação entre mídia e Direito Penal não pode ser concebida em prejuízo deste. A ênfase que se dá a este ramo, não é para mostrar seus 
resultados ou para conscientizar quanto a necessidade de mantê-lo de modo limitado e pontual, mas com uma tendência expansionista que só prejudica aos interesses dos cidadãos. A dignidade da pessoa humana não tem sido preservada quando a mídia interfere no âmbito penal, seja pela superexposição que faz aos acusados, condenando-os previamente, seja quando cria a representação do Direito Penal como instrumento único de política social, o instrumento solucionador de todas as mazelas sociais, mediante o uso da violência institucionalizada.

\section{EXPECTATIVAS SOCIAIS E DIREITOS FUNDAMENTAIS}

Numa sociedade em que há graves problemas sociais, em que se denota a ausência do Estado nas diversas instâncias, o Direito emerge como a solução dos problemas sociais. Todos os problemas que deveriam ser tratados por outras áreas são deslocados para que o Direito Penal apresente a solução, com a ideia de esta sanção ser a mais radical, mas olvida-se que nem sempre é a melhor ou a mais acertada para a situação.

Tem sido destacado que a mídia, agindo em detrimento da ação do Poder Judiciário, constitui uma ameaça para ação jurídica ao passar falsas informações ou a julgar os sujeitos antes dos agentes competentes para isso. Contudo, a articulação entre o campo jurídico e o campo midiático não se restringe a este aspecto. Esta é meramente a forma mais acintosa.

A comunicação midiática leva ao redimensionamento de outros campos sociais, como o campo jurídico, por exemplo. A partir da publicização de fatos atinentes ao Direito, especialmente o Penal, há a construção de uma representação sobre este campo, bem como o dimensionamento de questionamentos e exigências, a partir daquilo que é mostrado no campo midíático.

Por outro lado, com a linguagem e a gramática utilizada nestes dois campos é distinta e o campo jurídico, que é muito restrito, a imagem erigida pelo campo midiático prevalece e determina representação do campo jurídico para o senso comum, que passa a ter algumas representações distorcidas sobre elementos que compõem o campo jurídico. 


\section{MÍDIA E DIREITO PENAL: Articulação e Influência nos Direitos Fundamentais do}

Acusado

É neste contexto que se insere a discussão sobre as penas no Brasil, apresentadas como pequenas e insuficientes, ao serem atreladas a casos mostrados como absurdos, na lógica do grotesco, passam a ser criticadas pelo senso comum e constroi-se um pensamento da necessidade de majoração, quando não é um fator determinante para a ocorrência do delito posto em discussão.

Trata-se de um fenômeno análogo ao que Bourdieu descreve como decorrente da injunção da mídia jornalística sobre o campo político. Veja-se:

Segue-se que o império do campo jornalístico reforça as tendências dos agentes engajados no campo político a se submeterem à pressão das expectativas e das exigências da maioria, por vezes apaixonadas e irrefletidas, e frequentemente erigidas em reivindicações mobilizadoras pela expressão que recebem na imprensa. (1997).

A problemática da pena de morte é um exemplo clássico. A cada caso, em que há um crime pautado pela crueldade na ação e o fato é veiculado na Mídia, gera-se um notório clamor público, fazendo insurgir uma pressão popular para a inserção deste tipo de pena no ordenamento jurídico brasileiro. Não se discute sobre a possibilidade no sistema jurídico nacional, nem sobre sua real necessidade, mas um incitamento a apontar este tipo de pena como única saída viável diante de uma caso que é apresentado como absurdo.

A relação perpassa também a criação de uma ideia de que o Direito pode resolver os problemas sociais, agindo sobre a as questões sociais mais complexas, cuja manifestação mais pontual é o crime, mas que as bases estão em outras problemáticas.

Há um alargamento do âmbito da aplicação do Direito Penal, que passa a ser utilizado como instrumento de política social, sendo introduzido nas áreas as quais o Estado não consegue atingir de modo mais acertado. Isso com o intuito de aparentar socialmente a sensação de tranquilidade social e de um legislador atuante.

Assevera Fernanda Petrarca:

Essa ganância simbólica, na qual as garantias constitucionais e penais consagradas sucumbem às razões do Estado, que pretende impor o combate ao crime a qualquer custo, tem um alto custo, comprometendo a própria credibilidade do Direito Penal 
enquanto sistema. Chega-se, portanto, à crise de legitimidade vivenciada pelo Direito Penal na atualidade. Esse retrocesso punitivista, que converte o agente em inimigo social, não soa, portanto, a melhor solução para o enfrentamento da pósmodernidade. (2007).

Diante dos efeitos das representações, observa-se a aplicação do efeito da distorção em relação ao Direito Penal no que concerne à representação dele forjada pela mídia. Acresce-se a este ramo do Direito uma série de atributos que não lhes são pertencentes, como, por exemplo, a solução de problemas sociais.

O principal produto do jornalismo contemporâneo, a notícia, não é uma ficção, pelo menos em tese. Os acontecimentos ou os personagens das notícias não são, em princípio, invenções dos jornalistas. Até mesmo se pode falar que a transgressão da fronteira entre realidade e ficção pelos jornalistas é um dos maiores pecados da profissão.

Assim, com a montagem e a dramatização há, de fato, uma transformação de modo a tornar mais interessante a realidade, mas se paga o preço de deformar a realidade comunicada, o que tem ocorrido com o Direito Penal. "Nesse ponto, a tevê converte-se num veículo socialmente perigoso, pois tende a conformar o individuo à sua pseudo-objetividade”. (SODRÉ, 1977, p. 62).

Diante deste fenômeno decorrente da representação midiática é que se erigiu o conceito de Direito Penal Máximo. Este consiste num Direito Penal que é exacerbado e que se confunde com o instrumento de política social. Para o Direito Penal são nefastas as consequências deste tipo de utilização, haja vista o abandono da matriz principiológica que é sua diretriz, bem como a perda da coerência sistemática que deveria permear a ordem jurídica.

Logo, numa situação de crise social caracterizada pelo aumento da violência, a saída apresentada pela mídia é o endurecimento das leis penais, bem como a criação de mais estabelecimentos penais (penitenciárias), como se o sistema penal fosse suficiente para a solução da problemática social.

Este relativismo da incriminação apresenta importância patente ao se utilizar o Direito Penal como instrumento de Política Social. Assim, para a resolução dos problemas sociais lança-se 


\section{MÍDIA E DIREITO PENAL: Articulação e Influência nos Direitos Fundamentais do}

Acusado

mão da incriminação de condutas e da pujância das sanções penais contra as crises no tecido social, inclusive, desrespeitando a lógica do sistema penal.

[...] para oferecer a imagem de um Estado empenhado e ativo (inclusive penalmente) na persecução de maior número de metas propiciadoras de transformação social e da tutela de interesses de dimensões ultraindividual e coletivas, exaltando, continuadamente, o papel instrumental do direito penal com respeito à política criminal (PALAZZO apud SILVEIRA, 2007, p. 113).

A adoção de um punitivismo retrógrado contraria a todos os anos de evolução do Direito Penal em prol da garantia dos direitos individuais do cidadão. Colimou-se no decorrer dos anos tutelar o cidadão para que o Estado não fosse utilizado como seu inimigo, não tendo limites na aplicação de sanções.

Lutou-se para que se efetivasse a legitimidade do Direito Penal como último meio a ser utilizado diante de casos considerados graves, de modo a observar os valores previstos constitucionalmente, tais como o direito à liberdade e à dignidade da pessoa humana. Isso por meio de uma atuação limitada e objetiva, somente em casos extremos, ademais, sempre observando a proporcionalidade e a razoabilidade na intervenção.

Com o fenômeno expansivo do Direito Penal, cria-se, usando a expressão utilizada por Manuel Cancio Meliá, um "Direito Penal simbólico", uma vez que o fenômeno da neocriminalização cumpriria efeitos meramente simbólicos. Olvida-se o princípio da política criminal que enuncia que só a pena socialmente útil pode ser justa. O simbolismo do Direito Penal, neste contexto, é enfocado por seu viés negativo, conforme verbera o autor espanhol:

Quando se usa em sentido crítico o conceito de Direito penal simbólico, quer-se, então, fazer referência a que determinados agentes políticos tão-só perseguem o objetivo de dar a 'impressão tranqüilizadora de um legislador atento e decidido' (JAKOBS e MELIÁ, 2007, p. 59).

Este simbolismo se manifesta por meio do endurecimento das penas de normas já existentes, ou então, pela promulgação de normas que foram evidentemente criadas para não serem aplicadas, mas que surgiram como mecanismo para produzir a tranquilidade num contexto social de caos. 
Contra o expansionismo do Direito Penal, existe a corrente que recomenda a racionalização deste tipo de intervenção, limitando-o às situações problemáticas de absoluta irrenunciabilidade, tais como o terrorismo, seqüestro, latrocínio, homicídio etc. Esta minimalização tem por escopo fazer com que o Estado Democrático de Direito não seja compadecido com o emprego desnecessário ou desmedido da violência pública.

Alerta o jurista Paulo de Sousa Queiroz que:

E seguramente representa o direito penal uma das ramas menos recomendáveis de que pode dispor o Estado para acudir a segurança dos cidadãos, seja pelos custos sociais que ordinariamente implica, seja pelas imitações estruturais de sua atuação seletividade, localidade, excepcionalidade, contigencialidade, conseqüencialidade etc -, visa alcançar conflitos sociais já num estado avançado de desenvolvimento e de desgaste, Istoé, os alcança, por assim dizer num “estado terminal” (QUEIROZ, 2002, p. 22).

Convergindo com este pensamento, Heleno Cláudio Fragoso:

A prisão constitui realidade violenta, expressão de um sistema de justiça desigual e opressivo, que funciona como realimentador. Serve apenas para reforçar valores negativos, proporcionando proteção ilusória. Quanto mais graves são as penas e as medidas impostas aos delinqüentes, maior é a probabilidade de reincidência. $\mathrm{O}$ sistema será, portanto, mais eficiente, se evitar, tanto quanto possível, mandar os condenados para a prisão nos crimes pouco graves e se, nos crimes graves, evitar o encarceramento demasiadamente longo.(1991, p. 288).

Muniz Sodré relata o aspecto sensacionalista utilizado na televisão brasileira e agora, presente nos telejornais. Para ele o grotesco é a categoria estética mais apropriada para a apreensão do ethos escatológico da cultura de massa nacional. No grotesco se encaixa tudo aquilo que a primeira vista é inacessível à normalidade humana, tal como o demente, o aberrante, 0 macabro. Este aspecto de estranheza é apresentado pela cultura de massa como espetáculo, colocando-o perto do cômico e do caricatural. Face a uma sociedade do consumo e da sofisticação o grotesco, que é representado pelo aberrante, pelo miserável, apresenta-se como espetáculo, servindo de compensação para a angústia dos indivíduos dos grandes centros urbanos. 
A cultura de massa - frisamos: essencialmente política - é hoje o grande médium da atmosfera capitalista. No caso brasileiro, ela é também o espelho que reflete o id e os demônios de nossas estruturas. É o espelho em que a sociedade se olha e se oferece como espetáculo. (SODRÉ, 1977, p.39).

Nesse apelo à espetacularização é que se insere a veiculação de crimes, em que os acusados são previamente julgados e a narrativa dos fatos se dá como numa obra ficcional, distorcendo a realidade. Assim, transmuda-se a presunção de inocência, enquanto direito fundamental, em presunção de culpabilidade.

Nesse sentido, os direitos fundamentais, mormente relacionados aos acusados de crime, tem afetada sua legitimidade social em decorrência da práxis midiática que se apropria do processo penal na espetacularização da narrativa.

\section{CONCLUSÕES}

O poder da mídia reside, entre outros aspectos, na formação de representações, na influência que notoriamente exerce sobre outros campos, bem como na tradução na realidade social, o que no contexto hodierno, ocorre, até mesmo, a criação da realidade social, por meio da elaboração de acontecimentos para aparecer na mídia.

Diante deste quadro, e é um erro negligenciar a articulação entre a Mídia e o Direito Penal. Assim, entender como este diálogo tem-se efetivado é importante, inclusive, para compreender como isso repercute na legitimidade social deste ramo do Direito.

Falar em Direito Penal é falar, de alguma forma, em violência, não obstante a doutrina moderna sustente que a criminalidade é um fenômeno social normal. Contudo, não é válida a restrição do Direito Penal ao combate à violência, de modo fragmentado e sem relacionar com as diversas determinantes da violência. É este o discurso que tem a Mídia construído sobre este ramo. 
Num país em que são notórios os graves problemas sociais, tem-se construído a imagem do Direito Penal como solucionador das mazelas sociais. Assim, sem que haja prioridades nas áreas sociais, direciona-se a este ramo à possível solução dos conflitos sociais. Ocorre que não é a função deste ramo do Direito resolver as questões sociais, tampouco há capacidade para isso. Neste diapasão, faz-se mister a desconstrução deste errôneo paradigma.

A forma como a mídia, especialmente a televisiva por meio dos programas jornalísticos populares, tem representado o Direito Penal, não tem cumprido com a função social da Mídia junto à sociedade. Tem dominado o jornalismo de reverência à espetacularização e da ênfase à emoção, expurgando-se a reflexão.

Notabiliza pela busca do jornalismo enquanto atração, enquanto espetáculo para atrair o público, usando para tanto notas dramáticas envolvendo crimes. A espetacularização no tratamento dos crimes faz dos sujeitos envolvidos personagens numa trama, na qual fica difícil distinguir a realidade da ficção. Tudo isso construído com base na agressão a direitos fundamentais dos envolvidos, numa estratégia que, estranhamente, conta com participação do Estado, enquanto autoridade policial. Então, banaliza-se o fato do crime, com a exposição forçada e inadequada dos acusados, influenciando de modo decisivo no julgamento jurídico e social a que serão submetidos. Assim, é que é forjada a ideia de um Direito Penal máximo, que serve como único solucionador da criminalidade.

Distanciando-se da dimensão deontológica, a mídia jornalística, cada vez mais, tem apresentado a realidade na televisão por meio de uma dramatização que remonta a ideia de uma telenovela, isto é, há uma ficcionalização do real. Os fatos são apresentados quase sempre em pedaços, com uma narrativa seriada e apresentada de modo impressionar o telespectador e encantá-lo, assim foge da função denotativa da linguagem para se aproximar da função expressiva e emotiva. Há um convite à dramatização, com a busca do sensacional e do espetacular. Exagera-se em importância acontecimentos demarcando seu caráter trágico e dramático.

Percebe-se com todo o exposto que o interesse comercial ligado à manutenção da audiência, tem afetado a credibilidade da mídia ao se confrontar seu dever de informar com sua função social. Apresenta-se um contexto no qual os centros de poder utilizam a mídia para vender 


\section{MÍDIA E DIREITO PENAL: Articulação e Influência nos Direitos Fundamentais do}

Acusado

seus produtos ou ideias e transformam a notícia em espetáculo, exagerando ou banalizando questões, com o escopo de garantir a audiência. Olvida-se, assim, a responsabilidade com a informação e com o público que receberá aquilo que emite.

Fica patente o afastamento do ideal de relação entre mídia e esclarecimento, de fomentar uma atitude mais voltada è emancipação do indivíduo. É indubitável que o homem é um ser curioso e que a mídia objetiva atender a curiosidade do público. Faz mister, no entanto, não utilizar isso como justificativa para não privilegiar o interesse público em detrimento do fomento à inutilidade pública.

A leviandade do denuncismo e da narrativa da exacerbação do Direito Penal é muito prejudicial à garantia dos direitos individuais, expressivos num Estado Democrático de Direito.

\section{REFERÊNCIAS}

ANGHER, Anne Joyce (org.). Vade maecum acadêmico de direito. 2. ed. São Paulo: Rideel, 2005.

ARAGÃO, Rita de Cássia. A metástase da imagem: Um estudo sobre a representação da Exclusão social no Jornal Nacional. Tese apresentada à banca examinadora do Programa de Doutorado em Comunicação e cultura Contemporâneas da Universidade Federal da Bahia, 2002.

ARAGÃO, Rita de Cássia. Mídia: novos modos de interação e representação. IN: Revista Círculo. Salvador, ano 1, n. 1, v. 1. jul/dez. 2003.

BECHARA, Ana Elisa. Violência, mídia e direito penal de emergência . Sábado, 31 de maio de 2008. Boletim IBCCRIM $\mathrm{n}^{0} 186$ - maio / 2008. DIsponível em: < http://infodireito.blogspot.com/2008/05/artigo-violncia-mdia-e-direito-penal-de.html>. Acesso em: 12. jan. 2009.

BOURDIEU, Pierre. Sobre a Televisão. Rio de Janeiro: Jorge Zahar, 1997. 
. O Poder Simbólico. 11. ed. Rio de Janeiro: Bertrand Brasill, 2007.

- A opinião pública não existe. 2007.Disponível em: < http://uniaocomunista.blogspot.com/2007/07/opinio-pblica-no-existe.html>. Acesso em 10 de mar de 2018.

- Verdades e mentiras: O império do jornalismo. Disponível em:

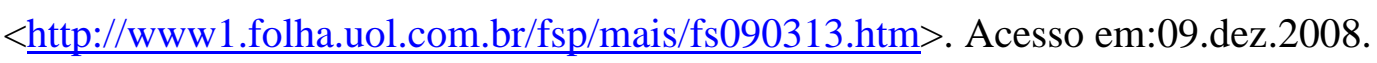

BITENCOURT, Cezar Roberto. Tratado de Direito Penal: parte especial. 4.ed. v. 2. São Paulo: Saraiva: 2004.

. Tratado de Direito Penal: parte geral. 8.ed. v. 1. São Paulo: Saraiva: 2003.

BRASIL, Constituição (1988). Constituição da República Federativa do Brasil. São Paulo: Manole, 2008.

BURSTYN Marcel (org.). No meio da Rua - nômades, excluídos e viradores. Rio de Janeiro: Garamond, 2000.

CANELA, Guilherme. Monitoramento da mídia, jornalismo e desenvolvimento. In: MOTTA, Luiz Gonzaga (orgs.). Observatórios da mídia: olhares da cidadania. São Paulo: Paulus, 2008.

CHAUI, Marilena. Simulacro e poder: uma análise da mídia. São Paulo: Editora Fundação Perseu Abramo, 2006.

CORDEIRO, Tânia. Mortes violentas e os tempos de luta por justiça. In: TAPARELLI, Gino. Vidas em risco: quando a violência e o crime ameaçam o mundo público e o privado. Salvador: Arcádia, 2008.

CHRISTOFOLETTI, Rogério. Ver, olhar, observar. In: CHRISTOFOLETTI, Rogério e MOTTA, Luiz Gonzaga. Observatórios de mídia: olhares da cidadania (orgs.). São Paulo: Paulus, 2008.

ERBOLATO, Mário. Técnicas de Codificação em Jornalismo. São Paulo: Ática, 2003. 
FERREIRA FILHO, Manoel Gonçalves. Direitos Humanos Fundamentais. São Paulo: Editora Saraiva, 1999.

FRAGOSO, Heleno Cláudio. Lições de Direito Penal - A nova parte geral. Rio de Janeiro, Forense, 13. ed. 1991.

GENTILI, Victor. O futuro do jornalismo: democracia, conhecimento e esclarecimento. In: CHRISTOFOLETTI, Rogério e MOTTA, Luiz Gonzaga. Observatórios de mídia: olhares da cidadania (orgs.). São Paulo: Paulus, 2008.

GUARESCHI, Pedrinho e BIZ, Osvaldo. Mídia, educação e cidadania - tudo o que você precisa saber sobre mídia. Petrópolis: Editora Vozes, 2005.

HAMILTON, Fernando. Monitorando telejornais: desafios e perspectivas. In: CHRISTOFOLETTI, Rogério e MOTTA, Luiz Gonzaga. Observatórios de mídia: olhares da cidadania (orgs.). São Paulo: Paulus, 2008.

JAKOBS, Günther e MELIÁ, Manuel Cancio. Direito Penal do Inimigo: noções e críticas. André Luis Callegari e Nereu José Giacomolli (trad e org.). 2. ed. Porto Alegre: Livraria do Advogado, 2007.

JODELET, Denise. Representações sociais: um domínio em expansão. In: (org.). As representações sociais. Rio de Janeiro: EdUERJ, 2001.

KOCHE, José Carlos. Fundamentos de Metodologia Científica. Petrópolis: Vozes, 2003.

LOURES, Ângela da Costa Cruz Loures. Pequena história da crítica da mídia no Brasil. In: CHRISTOFOLETTI, Rogério e MOTTA, Luiz Gonzaga. Observatórios de mídia: olhares da cidadania (orgs.). São Paulo: Paulus, 2008.

NEVES, Marcelo. A Constitucionalização Simbólica. São Paulo: Martins Fontes, 2007.

OLIVEIRA, Dijaci David de et al. Primavera já partiu: retrato dos homicídios femininos no Brasil. Brasil: MHDH, 1998.

PEREIRA, Wellington. A mídia e a construção do cotidiano. (uma epistemologia do social midiático). In: CHRISTOFOLETTI, Rogério e MOTTA, Luiz Gonzaga. Observatórios de mídia: olhares da cidadania (orgs.). São Paulo: Paulus, 2008. 
PEREIRA. Pedro Paulo. A violência nas narrativas. OLIVEIRA, Dijaci David de et al. Primavera já partiu: retrato dos homicídios femininos no Brasil. Brasil: MHDH, 1998.

PERELMAN, Chaim. Ética e Direito. Trad. Maria Ermantina Galvão. São Paulo: Martins Fontes, 2000.

PERELMAN, C. e OLBRECHTS-TYTECA, L.Tratado da Argumentação: a nova retórica. Trad. Maria Ermantina Galvão. São Paulo: Martins Fontes, 2002.

PETRARCA. Fernanda Rios. As Relações entre Mídia e Direito no Brasil: elementos para uma análise sociológica. Revista Sociologia Jurídica. N. 05 - Julho-Dezembro/2007. Disponível em: <http://sociologiajur.vilabol.uol.com.br/rev05ferpetrarca.htm.> Acesso em: 12.01.2009.

PIOVESAN, Flávia. Temas de Direitos Humanos. São Paulo: Max Limonad, 1988.

QUEIROZ, Paulo de Souza. Do caráter subsidiário do Direito Penal: lineamentos para um Direito Penal Mínimo. 2. ed. Belo Horizonte: Del Rey, 2002.

RUBIM, Antônio Albino. Sociabilidade, Comunicação e Política Contemporâneas: Subsídios para uma alternativa teórica. In: Textos de Cultura, Comunicação, Política e Poder. Fase 2. n. 27. Salvador: FACOM/UFBA, 1992.

SILVA, César Dario da. Tutela Penal da intimidade. Salvador: Editora Jus PODVIM, 2009.

SILVA, Cleide Bezerra da. A sociedade como refém. In: OLIVEIRA, Dijaci David de et al. Primavera já partiu: retrato dos homicídios femininos no Brasil. Brasil: MHDH, 1998.

SILVEIRA, Fabiano Augusto Martins. Da criminalização do racismo: aspectos jurídicos e sociocriminológicos. Belo Horizonte: Del Rey, 2007.

SPINK, Peter e SPINK, Mary Jane. Práticas cotidianas e naturalização da desigualdade: uma semana de notícias nos jornais. São Paulo: Cortez, 2006.

SODRÉ, Muniz. A comunicação do Grotesco: introdução à cultura de massa brasileira. 6. ed. Petrópolis: Vozes, 1977. 
SOULAGES. Jean-Claude. Instruemntos de análise de discurso nos estudos televisuais. In: LARA, Gláucia Muniz et al (orgs). Análises de discurso hoje. Rio de janeiro: Nova Fronteira., 2008.

TRAQUINA, Nelson. Teorias do Jornalismo. Florianópolis: Insular, 2004.

VIANNA, LUIZ WERNECK VIANNA. MÍDIA E DIREITO: A “JUDICIALIZACÃO” DAS RELAÇÕES SOCIAIS. 11. MAIO. 2008. DISPONÍVEL

EM:<HTTP://SUPREMOEMDEBATE.BLOGSPOT.COM/2008/05/MDIA-E-

DIREITO-JUDICIALIZAO-DAS-RELAES.HTML>. ACESSO EM 10 DE MAR DE 2018. 